\title{
Alçıtaşı üretiminde delme - patlatma yöntemi yerine mekanik kazı yönteminin kullanılabilirliğinin araştırılması
}

\author{
Investigation of the usability of mechanical excavation method instead of the \\ drilling-blasting method in the production of gypsum
}

\author{
Ramazan Çomaklı,** \\ Niğde Ömer Halisdemir Üniversitesi, Maden Mühendisliği Bölümü, 51240, Niğde Türkiye
}

\begin{abstract}
Özet
Dünyada ve ülkemizde açık işletme yöntemi kullanılarak üretimi yapılan endüstriyel hammaddelerin kazısın genellikle delme-patlatma yöntemi kullanılmaktadır. Patlatma etkisiyle tonlarca malzemenin aynı anda gevşetilip parçalandı̆̆ uygulamaları açık işletme yönteminde ekonomik olarak değerlendirilmektedir. Ancak özellikle düşük dayanımlı kayaçların kazısında mekanik kazıcıların alternatif kazı yöntemi olarak değerlendirilmesi mümkün olabilir. Kazılacak formasyonun dayanımının düşük olması daha kolay kazılabilmesine ve kazı performansının artmasına olanak sağlamaktadır. Ayrıca mekanik kazı yöntemlerinde yükleme ve nakliye gibi kazı sonrası yapılan çalışmalar daha ekonomik olarak yapılabilmektedir.

Bu çalışmada Niğde ili Ulukışla ilçesinde bulunan ve ABS Alçı firmasına ait alçıtaşı ocağında, delme-patlatma yöntemi yerine mekanik kazı yönteminin kullanılabilirliği araştırılmıştır. Delme-patlatma yönteminin maliyeti 5 farklı patlatma için hesaplanmış ve birim maliyet belirlenmiştir. Mekanik kazı yöntemi için de birim maliyet değerleri teorik olarak hesaplanmış ve bu iki yöntem maliyet bakımından kıyaslanmıştır.
\end{abstract}

Anahtar kelimeler: Alçıtaşı, Delme-patlatma, Mekanik kaz1, Maliyet

\section{Giriş}

Delme - patlatma yöntemi, kazı ve üretim amaçlı olarak maden ve tünel projelerinde kullanılan yöntemlerden birisi olup özellikle agrega ve endüstriyel hammadde üretiminde yaygın olarak kullanılmaktadır. Günümüz rekabet şartlarında firmalar için en önemli husus üretim maliyetlerini mümkün olduğu kadar en aza indirmektir. Delme ve patlatma yöntemi kullanılarak üretim yapılan işletmelerde genel olarak maliyeti oluşturan temel parametreler; delme, patlatma, kırma, eleme, yükleme ve nakliye işlemleridir. Köse ve diğ., [1] yaptıkları bir çalışmada agrega üretimi için maliyeti oluşturan temel parametrelerin etkilerini araştırmışlardır. İlgili çalışma sonucunda delme ve patlatma işlemlerinin toplam maliyet içerisindeki oranının yaklaşık \%30 olduğu belirlenmiștir. Delme - patlatma maliyetlerinin

\begin{abstract}
Drilling-blasting method is generally used in the excavation of industrial raw materials produced by open-pit mining method. Since tons of materials are loosened and crushed at the same time by blasting effect, drilling-blasting applications are considered as more economic production in open-pit mines. However, in the excavation of lowstrength rocks, the mechanical excavation is able to be used as an alternative production method. Decreasing in the strength of rock formation to be excavated not only allows for easier excavation but also increase excavation performance. In addition, many operations following rock excavation such as loading and transportation can be carried out more economically in the mechanical excavation method.

In this study, the usability of the mechanical excavation method instead of drilling-blasting method was investigated in the gypsum quarry of ABS firm in Ulukışla county of Niğde province. The cost of the drilling-blasting method was calculated for 5 different blasting operations, and the unit cost for each operation was determined. Unit cost values for the mechanical excavation method were also calculated theoretically. By taking into account for obtained results, these two excavation methods were compared in terms of their cost.
\end{abstract}

Keywords: Gypsum, Drilling-blasting, Mechanical excavation, Cost

toplam maliyete etkisinin anlaşılabilmesi ve bu etkilerin minimize edilebilmesi amacıyla da farklı araştırmacılar bu konuyu detaylı şekilde incelemiştir [2-5]. Delme-patlatma maliyetinin toplam maliyete oranı genel olarak kullanılan malzeme ve formasyon özelliklerine göre farklılık göstermekle birlikte, Bağdatlı [6] yaptı̆̆ı çalışmada genel olarak bu oranın \% 5-40 arasında değiştiğini belirtmiştir.

Delme ve patlatma işlemlerinin verimli yapılıp yapılmama durumu hiç şüphe yok ki toplam maliyet içerisindeki oranının değişiklik göstermesine sebep olmaktadır. Şöyle ki; verimsiz yapılan bir patlatma işleminden sonra ikinci bir patlatmaya ihtiyaç duyulabilmekte veya verimsiz patlatma yüksek patar oranının oluşmasına sebep olabilmektedir. Bu durumda ortaya çıkan büyük blokların nakliyesi ve kırılması işlemleri

* Sorumlu yazar / Corresponding author, e-posta / e-mail: rcomakli@ohu.edu.tr (R. Çomakl1)

Geliş / Recieved:19.01.2021 Kabul / Accepted:26.03.2021 Yayımlanma / Published: 27.07.2021

doi: $10.28948 /$ ngmuh.864550 
de fazladan masraf oluşturacak ve toplam maliyet artacaktır [7]. Kahriman [8] yaptığı çalışmada uygun olmayan bir delme - patlatma işleminin toplam maliyet üzerinde oldukça etkili olduğunu belirtmiştir. Benzer şekilde Hoek ve Bray [9] tarafından yapılan çalışmada daha küçük parçalar elde etmek için delme - patlatma maliyetinin artmasıyla toplam maliyetin artacağ 1 , buna karşın delme - patlatma maliyetinin düşürülmek istenilmesi durumunda ise daha büyük blokların elde edileceği ve bununda patarlama, nakliye ve kırma maliyetlerini artıracağı için yine toplam maliyetin artacağ belirtilmiştir. Bundan dolayı delme ve patlatma işleminin ilgili formasyon özelliğine ve istenilen malzeme özelliklerine göre optimize edilmesi gereklidir.

Bir patlatma işleminin verimli olup olmadığ farklı parametre ile ölçülebilmektedir [9]. Verimsiz şekilde yapılacak olan patlatma işlemi takip eden sonraki işlemlerin de aksamasına ve maliyetin artmasına sebep olmaktadır ve bu konuda yapılmış birçok araştırma literatürde mevcuttur [10-12, 4, 13]. Arpaz [14] ve Bilim vd. [15] yaptıkları çalışmalarda verimsiz bir patlatma işleminin zamanın verimli kullanımını, makine seçimini ve maliyeti büyük ölçüde etkilediğini belirtmişlerdir. Verimsiz bir patlatma özellikle yükleyici performansını da olumsuz etkileyecektir [16-18, 8]. Elde edilen tüm sonuçlara göre formasyon özelliklerine göre optimum delme - patlatma tasarımının yapılmasının toplam maliyet üzerinde ne kadar etkili olduğu anlaşılmaktadır. Ancak özellikle küçük işletmeler tarafından herhangi bir ön çalışma yapılarak üretim için en uygun delme ve patlatma yönteminin seçimine yönelik bir optimizasyon yapılmamakta ve bu durum da firmaların ekstra maliyetlerle karşılaşmalarına sebep olmaktadır.

Bununla birlikte delme ve patlatma yönteminin çeşitli dezavantajları da bulunmaktadır. Yöntemin en önemli dezavantajlarından birisi özellikle yerleşim yerlerine yakın yerlerde yürütülen madencilik ve tünel kazı projelerinde çevreye vereceği olumsuz etkilerdir. Bu olumsuz etkiler genel olarak taş savrulması, hava şoku, toz emisyonu ve yer sarsıntısı şeklinde olmaktadır [19]. Özellikle literatürde patlatma sonucunda oluşacak yer sarsıntısının (titreşim) azaltılması ve yerleşim yerlerine etkilerini azaltmak için yapılmış birçok çalışma bulunmaktadır [20-23]. Tüm bu dezavantajlar göz önüne alındığında delme-patlatma yöntemine alternatif bir kazı yöntemi olarak mekanik kazıcıların varlığı değerlendirilebilmektedir.

Farklı araştırmacılar tarafından maden kazılarında, özellikle daha az sürede daha fazla üretime imkân tanımasından dolayı, delme - patlatma yöntemi yerine mekanik kazıcıların kullanılabilirliği araştırılmıştır [24-26]. Günümüzde özellikle yeraltı üretim yöntemi uygulanan birçok işletmede mekanik kazıcılar kullanılmakla birlikte özellikle endüstriyel hammadde veya agrega üretimi yapılan açı ocaklarda mekanik kazıcılar çok fazla kullanılmamaktadır. Bunun en büyük sebebi mekanik kazı yöntemlerinin uygulanmasını kısıtlayan ve özellikle de yüksek dayanıma sahip kayaçların varlığı gibi formasyon özelliklerine bağlı olan sebeplerdir [27, 28].

Yüksek dayanımlı kayaçların kazısında mekanik kazı yöntemi delme-patlatma yöntemine kıyasla ekonomik olmamakla birlikte, düşük dayanımlı hammaddelerin kazısında bu durumun farklı olacağ değerlendirilebilmektedir.

Yapılan bu çalışmada, Niğde bölgesinde üretimi yapılan düşük dayanımlı alçıtaşı kazısı için delme-patlatma yöntemi yerine mekanik kazı yönteminin kullanımının ekonomik olup olmadığı araştırılmıştır. Bu amaçla 5 farklı delmepatlatma uygulaması için birim maliyet belirlendikten sonra belirli özellikteki kollu galeri açma makinesi için teorik olarak birim maliyet hesaplanmıştır. Daha sonra her iki yöntem için elde edilen birim maliyetler karşılaştırmıştır.

\section{Materyal ve metot}

\subsection{Arazi çalışmaları ve delme-patlatma maliyet analizi}

$\mathrm{Bu}$ çalışma kapsamında delme-patlatma yöntemi kullanılan bir açık işletmede üretimi yapılan düşük dayanımlı bir endüstriyel hammaddenin kazısında delmepatlatma yöntemi yerine mekanik kazı yönteminin kullanılabilirliği araştırılmıştır. Bu kapsamda Niğde ili Ulukışla ilçesi sınırlarında bulunan ve ABS Alçı firmasına ait alçıtaşı ocağında çalışmalar yapılmıştır. İlgili işletme Ulukışla-Adana karayolu 9. km’ sinde bulunmakta olup, işletme de 15 işçi çalışmaktadır (Şekil 1). İşletmede alçıtaşı üretimi/kazısı hâlihazırda delme ve patlatma yöntemi ile yapılmaktadır.

Delme-patlatma uygulamalarının maliyetlerinin belirlenmesi için işletmede yapılan 5 farklı patlatma işlemi için maliyet hesaplaması ayrı ayrı olarak yapılmıştır. Maliyet hesaplamaları yapılırken delik delme ve patlatma işlemleri için yapılan çalışmalar detaylı olarak incelenmiş ve maliyetleri belirlenmiştir. Buna göre delme-patlatma maliyetleri genel olarak delik delmede harcanan yakıt, patlatmada kullanılan patlayıcı ve yardıme malzeme maliyetleri ve patlatma sonunda hidrolik kırıcı çalışmasına bağlı olarak ortaya çıkan yakıt maliyetleri şeklinde belirlenmiş. Her bir uygulamada patlatma düzeni $89 \mathrm{~mm}$ çapında dikey delikler açılarak iki sıra şeklinde uygulanmış olup, patlatma da ANFO, dinamit ve milisaniye gecikmeli kapsüller kullanılmıştır. Tüm patlatmalara ait detaylı veriler Tablo 1' de verilmiştir.

Delme-patlatma işlemlerinde yapılan işlemler detaylı olarak kaydedildikten sonra tüm işlemler için detaylı maliyet analizi yapılmıştır. Maliyet analizi yapılırken toplam maliyet ve her bir patlatma sonunda elde edilen üretim miktarı oranlanarak, delme-patlatma yönteminde $1 \mathrm{~m}^{3}$ malzeme üretiminin birim maliyeti belirlenmiştir. Elde edilen sonuçlar Tablo 2' de verilmiştir.

\section{Laboratuvar çalışmaları ve teorik hesaplamalar}

\subsubsection{Fiziksel ve mekanik testler}

Her bir delme-patlatma işlemi sonunda oluşan yığının en az 3 farklı bölgesinde blok numuneler alınmıştır. Blok numunelerden alınan karot numuneler üzerinde yapılan testler ile kayaçların fiziksel ve mekanik özellikleri belirlenmiştir. ISRM [29] standartlarına uygun olarak yapılan deneyler ile kayaçların tek eksenli basınç dayanımı, dolaylı çekme dayanımı, yoğunluk ve porozite değerleri belirlenmiştir 
Tablo 1. 5 farklı delme-patlatma uygulamasına ait detaylar.

\begin{tabular}{cccccccc}
\hline $\begin{array}{c}\text { Patlatma } \\
\text { No }\end{array}$ & Tarih & $\begin{array}{c}\text { Delik Sayıs1 } \\
(\mathrm{adet})\end{array}$ & $\begin{array}{c}\text { Delik Boyu } \\
(\mathrm{m})\end{array}$ & $\begin{array}{c}\text { S1k1lama } \\
\text { Boyu }(\mathrm{m})\end{array}$ & $\begin{array}{c}\text { Delikler A. } \\
\text { Mesafe }(\mathrm{m})\end{array}$ & $\begin{array}{c}\text { Patlayı1c1 } \\
\text { Miktar1 (kg) }\end{array}$ & $\begin{array}{c}\text { Delik Delme } \\
\text { Süresi }(\mathrm{dk})\end{array}$ \\
\hline 1 & 16.7 .2019 & 29 & 13 & 2,5 & 3 & 1537,00 & 2030 \\
2 & 19.7 .2019 & 23 & 16 & 2,5 & 2,8 & 1541,00 \\
3 & 26.7 .2019 & 28 & 13 & 2,5 & 2,8 & 1484,00 \\
4 & 05.8 .2019 & 23 & 16 & 2,5 & 2,8 & 1530,19 \\
5 & 22.8 .2019 & 23 & 16 & 2,5 & 3 & 1544,91 \\
\hline
\end{tabular}

Tablo 2. Delme-patlatma uygulamalarının maliyet dağılımı.

\begin{tabular}{cccccc}
\hline $\begin{array}{c}\text { Patlatma } \\
\text { No }\end{array}$ & $\begin{array}{c}\text { Patlatma Maliyeti } \\
(\mathrm{TL})\end{array}$ & $\begin{array}{c}\text { Patarlama } \\
\text { Maliyeti (TL) }\end{array}$ & $\begin{array}{c}\text { Toplam } \\
\text { maliyet }(\mathrm{TL})\end{array}$ & $\begin{array}{c}\text { Toplam } \\
\text { üretim }\left(\mathrm{m}^{3}\right)\end{array}$ & $\begin{array}{c}\text { Birim Maliyet } \\
\left(\mathrm{TL} / \mathrm{m}^{3}\right)\end{array}$ \\
\hline 1 & 11496,18 & 580,0 & 12076,18 & 3958,5 & 3,05 \\
2 & 10363,34 & 725,4 & 11088,74 & 3606,4 & 3,07 \\
3 & 10788,12 & 1015,56 & 11803,68 & 3567,2 & 3,31 \\
4 & 10196,36 & 725,40 & 10921,76 & 3606,4 & 3,03 \\
5 & 10398.76 & 435,24 & 10834 & 3864,0 & 2,80 \\
\hline
\end{tabular}

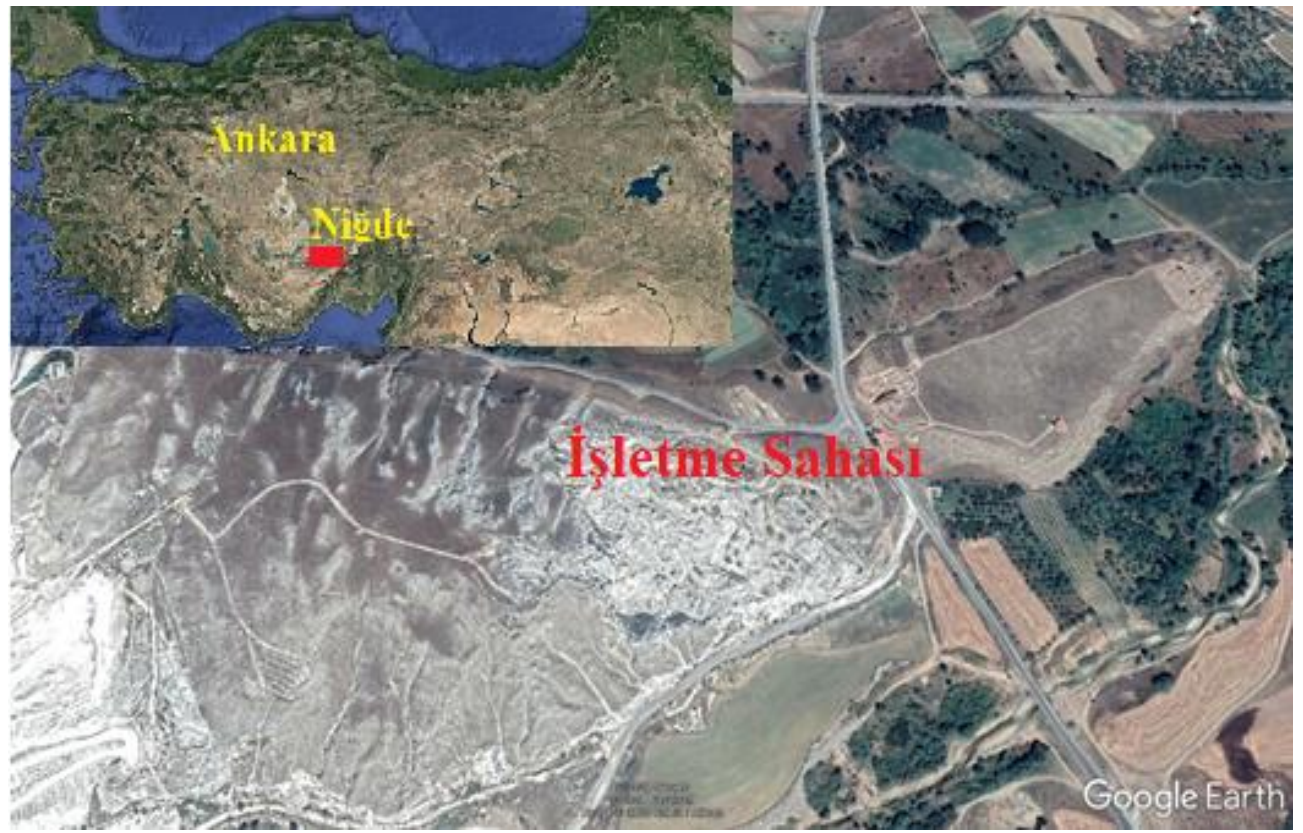

Şekil 1. ABS Alçı Ulukışla alçıtaşı işletme sahası.

Yapılan deneysel çalışmalarda her bir blok numunesinden en az 5 numune elde edilmiş ve her bir patlatma için en az 15 numune üzerinde testler yapılmış ve elde edilen değerlerin ortalaması alınarak nihai değerler elde edilmiştir. Yapılan deneyler sonunda elde edilen ortalama değerler Tablo 3' te verilmiştir.

Tablo 3. Laboratuvar deneyleri sonunda elde edilen ortalama değerler.

\begin{tabular}{ccccc}
\hline $\begin{array}{c}\text { Patlatma } \\
\text { No }\end{array}$ & $\begin{array}{c}\text { Yoğunluk } \\
\left(\mathrm{gr} / \mathrm{cm}^{3}\right)\end{array}$ & $\begin{array}{c}\text { Porozite } \\
(\%)\end{array}$ & $\begin{array}{c}\text { UCS } \\
(\mathrm{MPa})\end{array}$ & $\begin{array}{c}\text { BTS } \\
(\mathrm{MPa})\end{array}$ \\
\hline 1 & 2,17 & 29,48 & 14,5 & 2,58 \\
2 & 2,24 & 27,63 & 15,2 & 2,72 \\
3 & 2,18 & 28,21 & 14,1 & 2,64 \\
4 & 2,29 & 27,54 & 15,3 & 2,78 \\
5 & 2,32 & 26,69 & 15,8 & 2,84 \\
\hline
\end{tabular}

\subsubsection{Teorik spesifik enerji değerinin hesaplanması}

Mekanik kazı yöntemlerinin kullanıldığı kazı projelerinde maliyeti etkileyen en önemli parametrelerden birisi kazı esnasında harcanan enerjidir. Kazılacak formasyon özelliklerine uygun olarak makine tasarımlandırılması aşamasında harcanacak enerji göz önünde bulundurulmakta ve planlamalar buna göre yapılmaktadır. $\mathrm{Bu}$ doğrultuda projelendirme aşamasında yaygın olarak kullanılan yaklaşım, birim hacim malzemenin kazılması için harcanan enerji olarak tanımlanan spesifik enerji değerinin formasyon özelliklerine bağlı olarak belirlenmesidir. Spesifik enerji değeri kaya kesme deneyleri yardımıyla belirlenmektedir. Ancak, gerek bu deney setlerinin ülkemizde ve dünyada çok sayıda olmamasından ve gerekse deney prosedürünün zor olmasından dolayı spesifik enerji değerinin dolaylı olarak tahmin edilebilmesi için araştırmacılar farklı eşitlikler önermişlerdir [30-32].

Çopur ve diğ., [30] yaptıkları çalışmada Türkiye' nin farklı bölgelerinden alınan cevherler üzerinde yardımlı kaya 
kesme deneyleri yapmışlardır. Yapılan bu çalışma sonunda cevherlerin tek eksenli basınç (UCS) ve dolaylı çekme dayanımına (BTS) bağlı olarak optimum spesifik enerji değerinin tahmini için aşağıdaki eşitlikleri önermişlerdir;

$$
\begin{gathered}
\text { Opt. } S E=0,192 x U C S-2,22 \\
\text { Opt. } S E=1,676 x B T S-1,75 \\
\text { Opt. } S E=0,027(\text { UCSxBTS })+0,675
\end{gathered}
$$

Benzer bir çalışma Balcı ve diğ., (2004) tarafından farklı kayaçlar kullanılarak yapılmıştır. Yapılan yardımsız kaya kesme deneyleri sonucunda, $5 \mathrm{~mm}$ kesme derinliğinde elde edilen spesifik enerji değeri ile kayaçların dayanım özellikleri arasında aşağıdaki eşitlikleri önermişlerdir;

$$
\begin{gathered}
S E=0,37 x U C S^{0,86} \\
S E=3,36 x B T S^{0,71} \\
S E=1,16 x(\text { UCS } x B T S)^{0,40}
\end{gathered}
$$

Başka bir çalışmada Niğde ve Kayseri bölgesindeki farklı metalik cevherlerin kazısında kollu galeri açma makinesinin kullanılabilirliği araştırılmıştır [26]. Bu çalışmada küçük boyutlu kazı deney seti kullanılarak yardımsız kaya kesme deneyleri yapılmış ve spesifik enerji değerleri belirlenmiştir. Belirlenen spesifik enerji değerleri ile cevherlerin kırılganlık değerleri arasındaki ilişkiler araştırılmış ve kırılganlık değerlerine bağlı olarak kollu galeri açma makinesi spesifik enerji değerinin tahmini için aşağıdaki eşitlik geliştirilmiştir;

$$
S E=0,078(U C S x B T S / 2)+7,37
$$

$\mathrm{Bu}$ çalışmada ABS Alçı firmasına ait Ulukışla alçıtaşı ocağında mekanik kazı yönteminin uygulanması durumunda oluşacak birim maliyet tahmin edilmiştir. Bu kapsamda ilgili işletmede üretimi yapılan alçıtaşının dayanım özelliklerine bağlı olarak belirli özellikteki bir kollu galeri açma makinesi için birim maliyet analizi yapılmıştır. Bu kapsamda da yukarıda verilen eşitlikler kullanılarak 5 farklı patlatmadan elde edilen alçıtaşı numunelerinin Tablo 3' te verilen tek eksenli basınç ve dolaylı çekme dayanımı değerlerine bağlı olarak kollu galeri açma makinesinin harcayacağı spesifik enerji değerleri hesaplanmıştır (Tablo 4). Hesaplanan bu değerlere göre de bu işletmede alçıtaşı kazısı için kollu galeri açma makinesi kullanılması durumunda oluşacak maliyet belirlenmiştir. Maliyet hesaplaması yapılırken $1 \mathrm{kwh}$ elektrik 0,54 TL olarak hesaplanmıştır. Yapılan tüm hesaplamalar sonucunda elde edilen maliyetler Tablo 5' te verilmiştir.

\section{Bulgular ve tartışma}

Alçıtaşı üretiminde klasik delme-patlatma uygulaması sırasında maliyeti oluşturan tüm işlemler detaylı olarak analiz edilmiş ve 5 farklı patlatma için metreküp başına birim maliyet hesaplanmıştır. Hesaplanan bu değerlere makine bakım maliyetleri gibi değişkenler ilave edilmemiştir. Yine bu yöntemde patlatma sonrası oluşan yı̆̆ının kamyonlara yüklenmesi sırasında ekskavatör çalışmasına bağlı olarak oluşacak maliyetler de maliyet hesaplamasına dâhil edilmemiştir.

Benzer şekilde mekanik kazı maliyetleri hesaplanırken de makine ve sistemin ilk yatırım ve bakım onarım maliyetleri hesaplamalara dâhil edilmemiştir. Farklı araştırmacılar tarafından önerilen 7 farklı modele göre teorik olarak kollu galeri açma makinesi enerji tüketimi maliyetleri hesaplanmıştır.

Yapılan hesaplamalar sonunda 5 farklı delme-patlatma uygulaması için birim maliyet değerleri 4,79 - 5,89 TL aralığında olarak belirlenmiştir. $\mathrm{Bu}$ maliyetlerin delik sayısına, iklim şartlarına ve formasyon özelliklerine bağlı olarak değişim gösterdiği söylenebilir. Mekanik kazı yöntemi için yapılan hesaplamalar da ise belirli özellikte seçilen bir kollu galeri açma makinesi için teorik hesaplamalar yapılmıştır. Hesaplamalar yapılırken kazılan formasyonun tek eksenli basınç ve dolaylı çekme dayanımları ile yine bu değerlere bağlı olarak hesaplanan kırılganlık değerleri kullanılmıştır. Farklı modellere göre yapılan hesaplamalar sonucunda en düşük maliyet değerinin, Çopur ve diğ., [30] tarafından kayaçların tek eksenli basınç dayanımı değeri kullanılarak elde edilen model kullanılarak hesaplandığ1 görülmektedir. En yüksek maliyet değerlerinin ise kayaçların dolaylı çekme dayanımı değerlerine bağlı olarak Balcı ve diğ., [31] tarafından geliştirilen modelden elde edildiği görülmektedir. Ancak genel olarak bakıldığında alçıtaşı üretiminde mekanik kazı yönteminin uygulanması durumunda karşılaşılacak maliyetin, klasik delme patlatma maliyetinden düşük olacağ 1 görülmektedir (Şekil 2). Şekil 2' de görüldüğü gibi klasik delme - patlatma uygulamasının 5 farklı patlatma için de farklı modellerden elde edilen teorik kazı maliyetlerinden fazla olduğu görülmektedir. $\mathrm{Bu}$ durumda birinci etken parametre kazılan alçıtaşı formasyonun düşük dayanımlı olmasıdır. Bununla beraber ilgili işletmede delme - patlatma uygulamasının optimize edilmesi ile de maliyetlerin düşürülebileceği söylenebilir. Ancak alçıtaşı gibi düşük dayanımlı endüstriyel hammaddelerinin kazısında kollu galeri açma makinesi gibi mekanik kazıcıların kullanımının daha ciddi şekilde ele alınması mümkün olabilir. Nitekim bölgede alçıtaşı kazısı için farklı mekanik kazıcıları deneyen firmalar bulunmaktadır.

Bununla birlikte delme patlatma yöntemi yerine mekanik kazıcıların kullanılması aşamasında basamak yüksekliği ve genişliği gibi ocak içi tasarım parametrelerinin de değişeceği göz önünde bulundurulmalıdır. Mekanik kazıcıların kullanılacağı durumlarda basamak yüksekliğinin kazıcının kol yüksekliğine göre belirlenmesi ve basamak genişliğinin de kazıcının ve nakliye araçlarının kolay manevra yapabileceği şekilde tasarlanması gerekmektedir. Bu çalışmanın yapıldığı alçıtaşı ocağında üretim tek bir basamak olarak yüzeyden yapılmaktadır ve basamak yükseklikleri 12 $\mathrm{m}$ ve genişliği $25 \mathrm{~m}$ ' dir. $\mathrm{Bu}$ kapsamda, bu işletmede mekanik kazıcı kullanılması durumunda basamak yüksekliğinin kazıcıya uygun şekilde tasarlanması yeterli olacaktır. 
Tablo 4. Önceki modeller kullanılarak teorik olarak hesaplanan spesifik enerji değerleri $\left(\mathrm{kwh} / \mathrm{m}^{3}\right)$.

\begin{tabular}{cccccccc}
\hline Patlatma & \multicolumn{7}{c}{ Model/Eşitlik Numaras1 } \\
\cline { 2 - 8 } No & 1 & 2 & 3 & 4 & 5 & 6 & 7 \\
\hline 1 & 0,58 & 2,57 & 1,69 & 3,69 & 6,59 & 4,94 & 2,45 \\
2 & 0,72 & 2,81 & 1,79 & 3,84 & 6,84 & 5,14 & 2,50 \\
3 & 0,51 & 2,67 & 1,68 & 3,60 & 6,69 & 4,93 & 2,45 \\
4 & 0,74 & 2,91 & 1,82 & 3,86 & 6,94 & 5,20 & 2,51 \\
5 & 0,83 & 3,01 & 1,89 & 3,97 & 7,05 & 5,31 & 2,53 \\
\hline
\end{tabular}

Tablo 5. Belirlenen spesifik enerji değerlerine bağlı olarak hesaplanan birim maliyet değerleri (TL/ $\left.\mathrm{m}^{3}\right)$.

\begin{tabular}{cccccccc}
\hline Patlatma & \multicolumn{7}{c}{ Model/Eşitlik Numaras1 } \\
\cline { 2 - 8 } No & 1 & 2 & 3 & 4 & 5 & 6 & 7 \\
\hline 1 & 0,32 & 1,39 & 0,91 & 1,99 & 3,56 & 2,67 & 1,32 \\
2 & 0,39 & 1,52 & 0,97 & 2,07 & 3,69 & 2,78 & 1,35 \\
3 & 0,27 & 1,44 & 0,91 & 1,95 & 3,61 & 2,66 & 1,32 \\
4 & 0,40 & 1,57 & 0,98 & 2,09 & 3,75 & 2,81 & 1,35 \\
5 & 0,45 & 1,63 & 1,02 & 2,15 & 3,81 & 2,87 & 1,37 \\
\hline
\end{tabular}

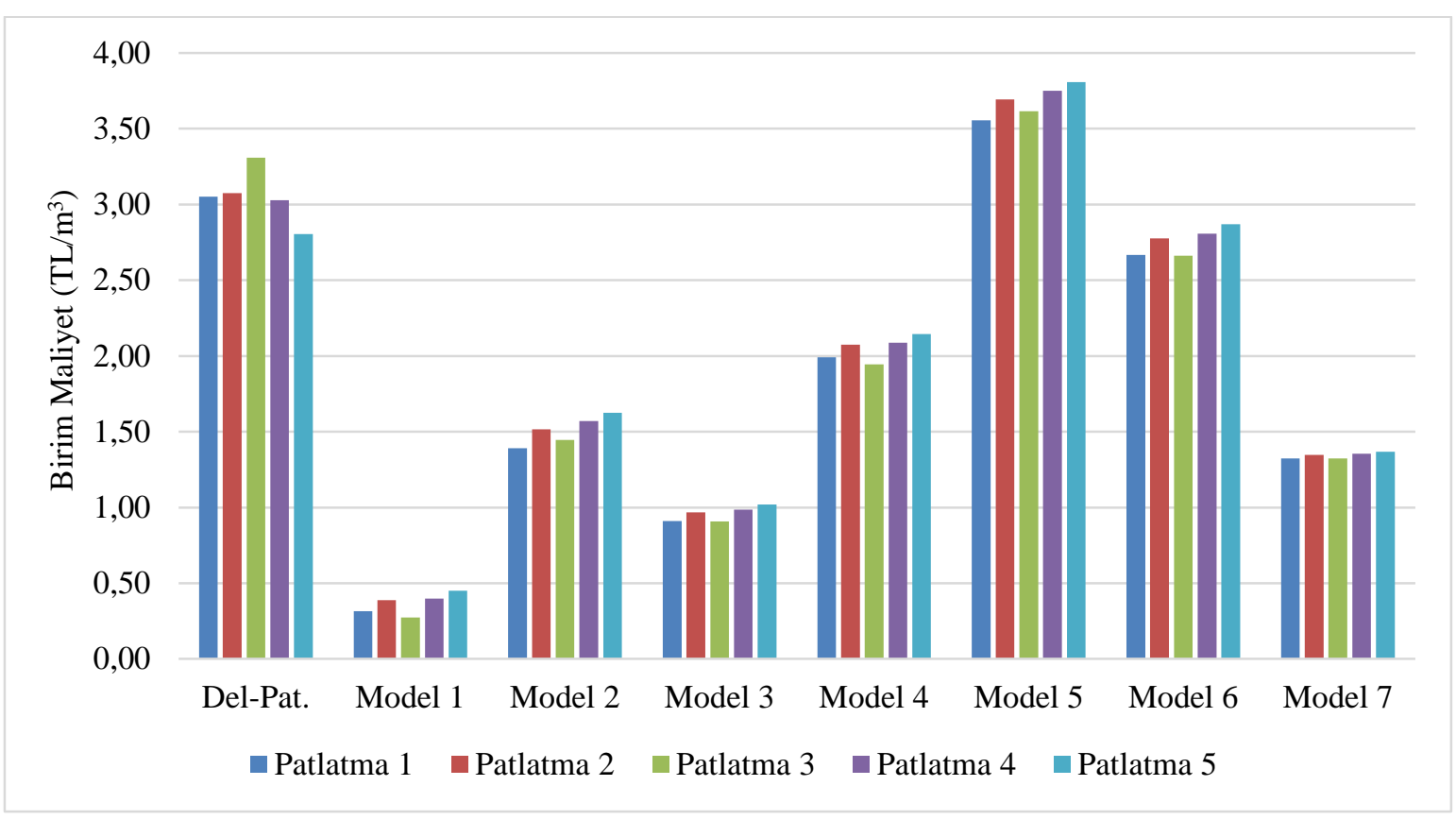

Şekil 2. Delme-patlatma uygulaması ile farklı teorik hesaplamalara göre mekanik kazı maliyetlerinin karşılaştırılması.

\section{Sonuçlar}

Bu çalışmada Niğde ili Ulukışla ilçesinde bulunan ve ABS Alçı firmasına ait alçıtaşı üretim sahasında klasik delme patlatma uygulaması yerine mekanik kazı yönteminin uygulanabilirliği birim maliyet bakımından incelenmiştir. Bu kapsamda 5 farklı patlatma için delme patlatma maliyeti detaylı olarak analiz edilmiş ve $1 \mathrm{~m}^{3}$ malzeme üretiminin maliyeti belirlenmiştir. Ayrıca farklı araştırmacılar tarafından önerilen modeller kullanılarak belirli özellikteki bir kollu galeri açma makinesi için $1 \mathrm{~m}^{3}$ malzemenin kazı maliyeti tahmin edilmiştir.

Daha sonra her iki yöntem için belirlenen maliyet değerleri karşılaştırılmış ve alçıtaşı üretiminde mekanik kazı yönteminin tercih edilmesi durumunda, üretimin daha düşük maliyetli olacağı belirlenmiştir. Ancak yapılan bu çalışma da mekanik kazı yöntemi için hesaplanan spesifik enerji ve birim maliyet değerlerinin teorik olarak hesaplandığ unutulmamalıdır. Spesifik enerji değerleri hesaplanırken kullanılan önceki modeller farklı dayanım değerlerine sahip farklı türdeki kayaçlar için elde edilmiştir. Bu yüzden daha doğru bir karşılaştırma için alçıtaşı numuneleri üzerinde kaya kesme deneyleri yapılmalıdır. İleride alçıtaşı üzerinde yapılacak kaya kesme deneyleri ile birlikte kaya kütle özelliklerini de göz önünde bulundurarak ilgili alçıtaşı ocağı için daha kapsamlı bir çalışma yapılması planlanmaktadır. Yine de kayaçların dayanım değerlerine göre geliştirilen bu modellerin kazı performansının tahmin edilmesinde yaklaşık sonuçlar vereceği düşünülmüştür. Ayrıca bu çalışma kapsamında incelenen ocakta üretimi yapılan alçıtaşının düşük dayanımlı olmasından dolayı da mekanik kazı maliyetinin delme - patlatma uygulaması maliyetine kıyasla daha düşük olacağı düşünülmektedir. 


\section{Teşekkür}

$\mathrm{Bu}$ çalışmanın yapılmasında gerekli olan arazi verilerini sağlayan ABS Alçı firmasına ve Maden Mühendisi Funda Akça' ya teşekkür ederim.

\section{Çıkar çatışması}

Bu çalışmanın kapsamında herhangi bir çıkar çatışması olmadığını beyan ederim.

\section{Benzerlik oranı (iThenticate): $\% 7$}

\section{Kaynaklar}

[1] H. Köse, F. Şimşir, T. Onargan ve E. Yalçın, Açık işletme tekniği. Dokuz Eylül Ǘniversitesi Mühendislik Fakültesi Yayınları, İzmir, 2009.

[2] C. O Aksoy, ve E. Yalçın, Kırmataş üretim yöntemlerinin ekonomik analizleri. 3. Endüstriyel Hammaddeler Sempozyumu, İzmir, 14-15 Ekim 1999.

[3] A. O. Yılmaz, R. Kaya, M. Şentürk, ve A. Tatarhan, 50/130/250/500 ton/saat kapasiteli kurma-eleme tesislerinin yatırım ve işletme maliyetlerinin belirlenmesi. 3. Ulusal Kırmataş Sempozyumu, İstanbul, 2003.

[4] A. Tosun, Muck pile fragmentation optimization at open pit bench blasting. PhD Thesis (in Turkish), Dokuz Eylul University, Institute of Science, İzmir, 2013.

[5] A. Tosun ve G. Konak, Determination of specific charge minimizing total unit cost of open pit quarry blasting operations. Arabian Journal of Geosciences, 8, 6409 - 6423, 2015. https://doi.org/10.1007/s12517014-1657-7.

[6] S. Bağdatlı, Üsküdar - Ümraniye - Çekmeköy metro hattı libadiye istasyonu yaklaşım tüneli kazısında yapılan patlatmalı kazılardan kaynaklanan titreşimlerin ölçülmesi ve çevresel etkilerinin değerlendirilmesi. Yüksek Lisans Tezi, Okan Üniversitesi Fen Bilimleri Enstitüsü, İstanbul, 2013.

[7] H. A. Bilgin ve A. G. Paşamehmetoğlu, Kayaların delinebilirlikleri ve patlatabilirlikleri üzerine bir çalışma. 1. Ulusal Kaya Mekaniği Sempozyumu, 113 125,1986

[8] A. Kahriman, Maden ve taşocaklarında kaya patlatma tekniği ve uygulamalar, Maden ve taşocaklarında kaya patlatma tekniği semineri. İstanbul, 2003.

[9] E. Hoek, and J. Bray, Rock Slope Engineering, Institution of Mining and Metallurgy. 3rd Edition, London, 1981.

[10] H. T. Özkahraman, H. A. Bilgin, Hâkim süreksizlik yönünün patlatmaya etkisi yerinde inceleme. 2. Delme ve Patlatma Sempozyumu, Ankara, 1996.

[11] A. Mortazavi, P. D. Katsabanis, Modelling the effects of discontinuity orientation, continuity, and dip on the process of burden breakage in bench blasting. Fragblast, 4 (3), 175-197, 2000.

[12] B. Aykan, The predictability of block size of blasted rock in calcite quarry using regression analysis and artificial neural networks method. Yüksek Lisans Tezi, Niğde Üniversitesi, Fen Bilimleri Enstitüsü, 2011.
[13] N. Bilim, A. Çelik, and B. Kekeç, A study in cost analysis of aggregate production as depending on drilling and blasting design. Journal of African Earth Sciences, 134, 564 - 572, 2017. https://doi.org/ 10.1016/ j.jafrearsci.2017.07.024.

[14] E. Arpaz, Türkiye'deki bazı açık işletmelerde patlatmadan kaynaklanan titreşimlerin izlenmesi ve değerlendirilmesi. Doktora Tezi, Cumhuriyet Üniversitesi, Fen Bilimleri Enstitüsü, 2000.

[15] N. Bilim, A. Çelik, and B. Kekeç, Determination of the effect of drilling-blasting operation on total cost in quarry. 8th Drilling-Blasting Symposium, 259-266, İstanbul, 2015.

[16] M. McGill, and J. Freadrich, The effect of fragmentation on loader productivity, Proceedings of 5th State of the Art Seminar on Blasting Technology. Instrumentation and Explosives Application, 713-724, 1994.

[17] P. R. Michaud, and J. Y. Blanchet, Establishing a quantitative relation between post blast fragmentation and mine productivity a case study. Proceedings of 5th International Symposium on Rock Fragmentation by Blasting, 386-396, 1996.

[18] S. P. Singh, and T. Yalçın, Effects of muck size distribution on scooping operations. Proceedings of 28th Annual Conference on Explosives and Blasting Techniques, 315-325, 2002.

[19] E. Değerli, Açık Ocak İşletmeciliğinde Basamak Patlatması Tasarımı, Bilimsel rapor, 63, 2012.

[20] G. R. Adhikari, A. I. Theresraj, S. Venkatesh, R. Balachander, R. N. Gupta, Ground vibration due to blasting in limestone quarries. Fragblast - International Journal of Blasting and Fragmentation, 8 (2), 85-94, 2004. https://doi.org/10.1080/13855140412331336160

[21] A. Kahriman, Ü. Özer, M. Aksoy, A. Karadığan, and G. Tuncer, Environmental impacts of bench blasting at hisarcık boron open pit mine in Turkey. Environmental. Geology, 50, 1015-1023, 2006.https://doi.org/10.1007/ s00254-006-0274-5.

[22] Ü. Özer, A. Karadoğan, A. Kahriman, and M. Aksoy, Bench blasting design based on site-specific attenuation formula in a quarry. Arabian Journal of Geosciences Journal, 6, 99711-721, 2013. https://doi.org/10.1007/s12517-011-0388-2.

[23] D. P. Blair, Blast vibration dependence on charge length, velocity of detonation and layered media. International Journal of Rock Mechanics and Mining Sciences, 65, 29-39, 2014. https://doi.org/10.1016/ j.ijrmms.2013.11.007.

[24] H. Tuncdemir, Investigation into application of boom type machines for mineral excavations. $\mathrm{PhD}$ Thesis. Istanbul Technical University, İstanbul, 2002.

[25] R. Çomaklı, Niğde ve Kayseri yöresindeki cevherlerin makine ile kazılabilirliklerinin belirlenmesi. Niğde Üniversitesi, Fen Bilimleri Enstitüsü, Yüksek Lisans Tezi, Niğde, 2010.

[26] R. Çomaklı, S. Kahraman, C. Balcı, D. Tumaç, Estimating specific energy from the brittleness indexes 
in cutting metallic ores. Tunnelling and Underground Space Technology, 116, 8, 763-768, 2016.

[27] J. Rostami, and L. Ozdemir, D. M. Neil, Performance prediction: a key issue in mechanical hard rock mining. Min. Eng. 1263-1267, 1994.

[28] N. Bilgin, H. Çopur, and C. Balcı, Mechanical excavation in mining and civil industries. CRC Press, Taylor \& Francis Group, Boca Raton, 2014.

[29] ISRM, In: Ulusay R, Hudson JA (eds) The Complete ISRM Suggested Methods for Rock Characterization, Testing and Monitoring: 1974-2006. Ankara, Turkey, 2007.

[30] H. Çopur, H. Tunçdemir, N. Bilgin, and T. Dinçer, Specific energy as a criterion for the use of rapid excavation systems in Turkish Mines. Transactions of the Institution of Mining and Metallurgy Section. A: Mining Technology, 110. A149-157, 2001.

[31] C. Balci, M. A. Demircin, H. Çopur, and H. Tunçdemir, Estimation of optimum specific energy based on rock properties for assessment of roadheader performance. Journal of the South African Institute of Mining and Metallurgy, 11. 633-641, 2004.

[32] R. Çomakli, S. Kahraman, C. Balci, and D. Tumac, Estimating specific energy from the brittleness indexes in cutting metallic ores. Journal of the Southern African Institute of Mining and Metallurgy 116, 763-768, 2016. doi:10.17159/2411-9717/2016/v116n8a8. 